\title{
Spectroscopic analysis of the interaction between tetra-( $p$-sulfoazophenyl-4-aminosulfonyl)-substituted aluminum (III) phthalocyanines and serum albumins
}

\author{
Liqin Zheng*, Yipeng He*, Pingping Lin ${ }^{\dagger}$, Lina Liu*, Hongqin Yang*, \\ Yiru Peng, ${ }^{*,+, \uparrow, \uparrow}$ and Shusen $\mathrm{Xie}^{*, \S, \boldsymbol{q}}$ \\ *Key Laboratory of Optoelectronic Science and Technology \\ for Medicine of Ministry of Education \\ Provincial Key Laboratory for Photonics Technology \\ College of Photonic and Electronic Engineering \\ Fujian Normal University, Fuzhou, 350007, P. R. China \\ ${ }^{\dagger}$ Provincial Key Laboratory of Polymer Materials \\ College of Chemistry and Materials Science \\ Fujian Normal University, Fuzhou, 350007, P. R. China \\ †yirupeng@fjnu.edu.cn \\ \$ssie@fjnu.edu.cn
}

Received 29 January 2016

Accepted 22 May 2016

Published 7 July 2016

\begin{abstract}
The binding interaction between tetra-( $p$-sulfoazophenyl-4-aminosulfonyl)-substituted aluminum (III) phthalocyanine (AlPc), and two-serum albumins (bovine serum albumin (BSA) and human serum albumin (HSA)) has been investigated. AlPc could quench the intrinsic fluorescence of BSA and HSA through a static quenching process. The primary and secondary binding sites of AlPc on BSA were domain I and III of BSA. The primary binding site of AlPc on HSA was domain I, and the secondary binding sites of AlPc on HSA were found at domains I and II. Our results suggest that AlPc readily interact with BSA and HSA implying that the amphiphilic substituents AlPc may contribute to their transportation in the blood.
\end{abstract}

Keywords: Phthalocyanine; BSA; HSA; fluorescence spectroscopy; UV-Vis spectroscopy.

\section{Introduction}

Photodynamic therapy (PDT) is a noninvasive treatment modality for several diseases, such as solid cancers, ${ }^{1}$ port wine stains,$^{2}$ wet age-related macular degeneration $(\mathrm{AMD})^{3}$ and so on. PDT treatment evolved utilizing an appropriate light

\Corresponding authors.

This is an Open Access article published by World Scientific Publishing Company. It is distributed under the terms of the Creative Commons Attribution 4.0 (CC-BY) License. Further distribution of this work is permitted, provided the original work is properly cited. 


\section{Zheng et al.}

wavelength to excite the injected photosensitizers which accumulated in tumor issue and then generates singlet oxygen or/and other reactive oxygen species (ROS). ${ }^{4,5}$ Photosensitizers, light, and oxygen are three basic components. Although many photosensitizers have been reported for their potential of application in PDT, such as photofrin, hematoporphyrin derivatives, 5-aminolevulinic acid (ALA) and silicon phthalocyanine (Pc4), ${ }^{6-8}$ so far there are only a few photosensitizers under clinical applications. It might be the results of hydrophobia and poor photophysical and physicochemical properties of these photosensitizers. Therefore, new photosensitizers with better hydrophilia property and excellent photophysical and physicochemical properties are in great demand.

Phthalocyanines (Pcs), a class of aromatic macrocycles, are regarded as the most promising second generation photosensitizer as because of their high fluorescence quantum yield, long triplet lifetimes, strong absorption at near infrared region, relatively low dark toxicity, high singlet oxygen quantum yield and readily chemical modification. ${ }^{5,9,10}$ Pcs have been used in many fields including the PDT applications. ${ }^{9}$ In PDT applications, photosensitizers are injected directly into the patients' blood vessel, so it is important to investigate the interaction between the photosensitizers and blood proteins. Serum albumin is the main constituents of plasma protein which is responsible for the binding and delivery of endogenous and exogenous substances such as fatty acids, hormones, and drugs. Furthermore, the drug delivery to cells in vivo and in vitro can be modulated according to the apparent solubility of the hydrophobic drug in plasma, so it is important to investigate the interaction between a drug and serum albumin.

According to the previous report,${ }^{11}$ bovine serum albumin (BSA) and human serum albumin (HSA) display approximately $76 \%$ sequence homology and a similar folding. Their structures have been welldocumented (Fig. 1). But there are differences in the number and location of tryptophan residues between them. Tryptophan residue has intrinsic fluorescence. BSA contains three homologous domains (I, II, III) and two tryptophan residues (Trp-134 and Trp-212). Trp-134 is on the surface of the protein molecule (domain I), whereas Trp212 lies in the bottom of the hydrophobic pocket in domain II. HSA contains three structurally similar domains (I, II, III) and only one tryptophan residue (Trp214), located within the hydrophobic pocket in domain II. The fluorescence of tryptophan residue is sensitive to the surrounding microenvironment, hence it has been a powerful tool to investigate small molecule- or nanoparticle-BSA/ HSA interactions. ${ }^{5,12-15}$

The solubility of Pcs plays an essential role in their applications, so different kinds of methods have been used to modulate their solubility.
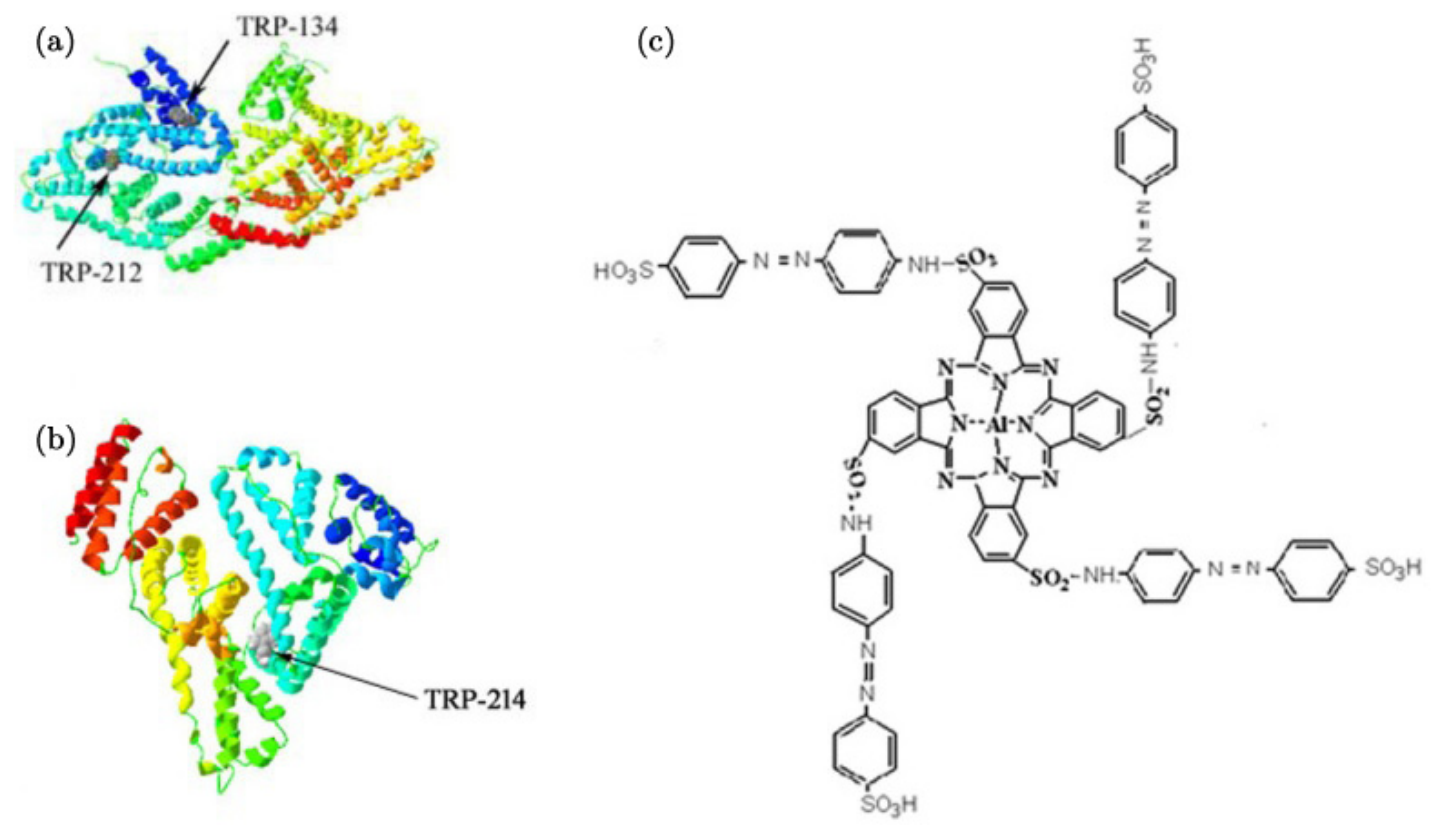

Fig. 1. Chemical structures of BSA (a), HSA (b) and AlPc (c). Tryptophan residues are in gray color. 
Therefore, many substituted Pcs have been synthesized. ${ }^{16-19}$ We have synthesized a novel AlPc, ${ }^{12}$ and the PDT efficacy of AlPc against the human umbilical cord blood endothelial cell (HUVEC) has been assessed in order to study its potential application in treatment of choroidal neovascularization $(\mathrm{CNV}) .{ }^{20}$ In this study, the interaction between $\mathrm{AlPc}$ and BSA/HSA by fluorescence and UVvisible spectroscopic method were further assessed in aim to explore the potential application of AlPc in PDT. The binding of AlPc to BSA and HSA was further investigated by a competitive binding approach.

\section{Materials and Methods}

\subsection{Materials}

BSA and HSA were purchased from Sigma-Aldrich (St Louis, MO), and dissolved in PBS to prepare a stock solution with concentration of $1.0 \times$ $10^{-3} \mathrm{~mol} / \mathrm{L}$. It was stored at $4^{\circ} \mathrm{C}$ in the dark. The AlPc complex was synthesized and characterized by our lab. ${ }^{12}$ The stock solution of AlPc complex was prepared in distilled water at $1.0 \times 10^{-4} \mathrm{~mol} / \mathrm{L}$. Hemin chloride (HE), Ibuprofen (IB) and L-tryptophan (TRP) were purchased from Sigma-Aldrich (St Louis, MO). Stock solutions of HE, IB and TRP were prepared in distilled water at $1.0 \times$ $10^{-3} \mathrm{~mol} / \mathrm{L}, 1.0 \times 10^{-3} \mathrm{~mol} / \mathrm{L}$ and $1.0 \times 10^{-1} \mathrm{~mol} / \mathrm{L}$, respectively.

\subsection{Equipment and spectral measurements}

The UV/Vis spectra of AlPc was studied on a Varian Cary 50 UV-Vis Spectrophotometer (Varian, USA). ${ }^{5}$ The concentration of AlPc complex was $1.0 \times 10^{-5} \mathrm{~mol} / \mathrm{L}$.

The fluorescence spectra of AlPc and HSA (BSA) conjugates was recorded on an Edinburgh FLFS920 TCSPC fluorescence spectrophotometer. ${ }^{5}$ The concentration of BSA and HSA was $1.0 \times 10^{-5} \mathrm{~mol} / \mathrm{L}$, while the concentration of AlPc complex ranged from 0 to $1.2 \times 10^{-5} \mathrm{~mol} / \mathrm{L}$.

\subsection{Binding sites investigation}

In order to investigate the binding sites of AlPc on the serum albumins, the UV-visible absorption spectroscopy of AlPc and serum albumins conjugates were studied by titration method by three specific probes. The three specific probes are HE, IB and TRP, which are the special probes for sites I, II and III of the serum albumins' domains, respectively. The molecular ratios of $\mathrm{AlPc}$ to $\mathrm{HE}$, IB and TRP were found to be $1 / 20,1 / 20$ and $1 / 1000$, respectively. The absorption spectra were measured with a Varian Cary 50 UV-Vis Spectrophotometer (Varian, USA). Background was corrected by subtracting absorption of water and PBS for AlPc complex and serum albumins. The studies were performed at room temperature.

\section{Results and Discussion}

\subsection{Aggregation studies}

Pcs have strong tendency to form aggregates in aqueous solution. This aggregation behavior is not preferred for their application in PDT, for it may reduce the excited-state lifetime mainly through internal conversion. ${ }^{21}$ Since UV-Vis absorption spectroscopy is a very simple and suitable method to investigate the structural change and to know the complex formation, ${ }^{22}$ the aggregation behavior of $\mathrm{AlPc}$ in the presence of BSA and HSA is performed using this method.

$\mathrm{Pc}$ has two absorption spectra in the UV/Vis region. One is $\mathrm{B}$ and the other is $\mathrm{Q}$ band. They are responsive to the electron transfer of $\pi\left(a_{1 u}\right)-\pi^{*}(\mathrm{eg})$ (B and) and $\pi\left(a_{1 g}\right)-\pi^{*}(\mathrm{eg})$ (Q band). The $\mathrm{B}$ band is not sensitive to the background, while electron density of the Pc ring can change the position and intensity of $\mathrm{Q}$ band. The absorption spectra of AlPc was shown in Fig. 2. There were two peaks in the Q band region in curve E. $687 \mathrm{~nm}$ was assigned to the monomer, and $658 \mathrm{~nm}$ was attributed to the absorption of dimer. It suggested that the AlPc mainly exist as dimer in water. ${ }^{23,24}$ Remarkable changes in the $\mathrm{Q}$ band region were observed in the presence of BSA (Fig. 2(a)) and HSA (Fig. 2(b)). With the increase of the concentration of the serum albumins, the absorption of dimer gradually decreased, while the peak of monomer gradually increased. The results suggested that the added BSA and HSA result in monomerization of the AlPc. However, the peaks at around $687 \mathrm{~nm}$ were increased to different extent, from 0.42 to 0.67 for BSA, from 0.66 to 0.96 for HSA. It might be the result of the different molecular weights and structures of the two different serum albumins. These observations strongly 


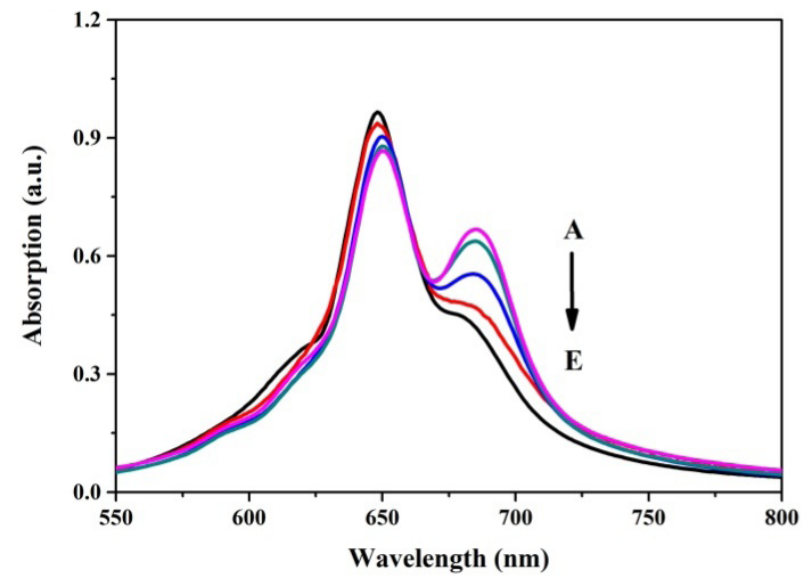

(a)

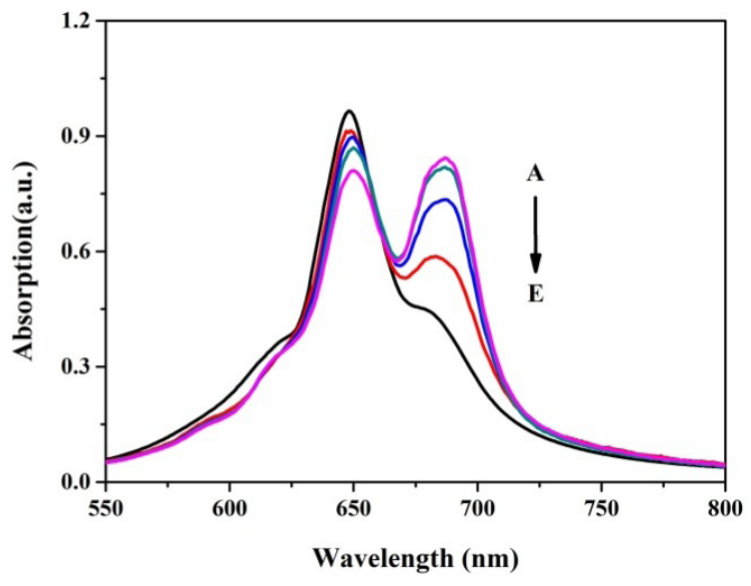

(b)

Fig. 2. Aggregation behavior of AlPc in water in the presence of BSA (a) and HSA (b) at various concentrations: A (pink): $1.2 \times 10^{-5}$; B (dark cyan): $0.8 \times 10^{-5}$; C (blue): $0.5 \times 10^{-5}$; D (red): $0.2 \times 10^{-5} ; \mathrm{E}$ (black): $0 \mathrm{M}$.

evidenced that BSA and HSA interaction with AlPc could inhibit the formation of aggregation of AlPc, thus improve its mono dispersity.

\subsection{Affinity measurements}

In the present study, the interaction between AlPc and BSA or HSA was investigated by fluorescence spectroscopic method. Figure 3 showed the fluorescence emission spectra of BSA (Fig. 3(a), curve A) and HSA (Fig. 3(b), curve A) in PBS. The maximum fluorescence emission wavelengths of BSA and HSA centered at around $344 \mathrm{~nm}$ and $358 \mathrm{~nm}$ respectively upon excitation at $280 \mathrm{~nm}$, arising from Trp fluorescence. ${ }^{25}$ For AlPc-BSA complex as well as AlPc-HSA complex, the fluorescence intensity gradually decreased with the increase of AlPc concentrations, and a shift of the maximum emission wavelength was also observed from $344 \mathrm{~nm}$ to $356 \mathrm{~nm}$ for BSA, and from $358 \mathrm{~nm}$ to $380 \mathrm{~nm}$ for HSA. These results suggested that microenvironment of the Trp residues changed, by means of an interaction between AlPc and serum albumins (BSA and HSA), leading to a ground-state complex formation. Besides, these results also suggested that the conformation of AlPc changed more

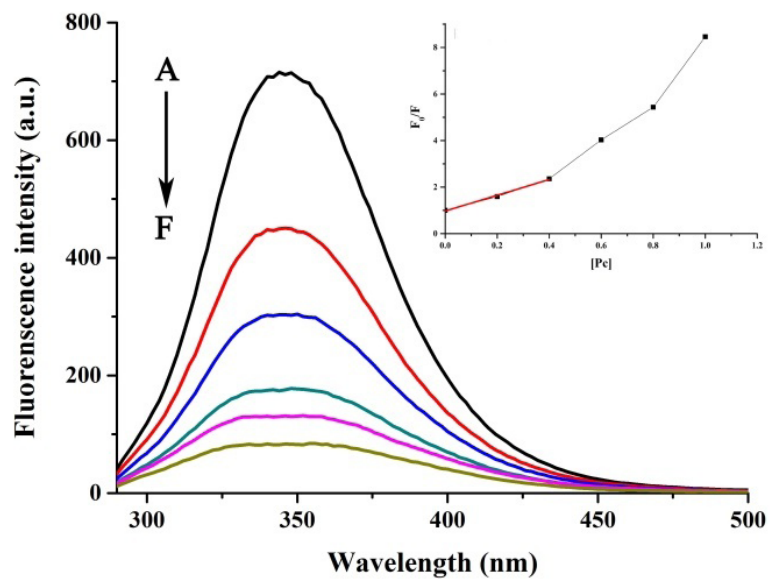

(a)

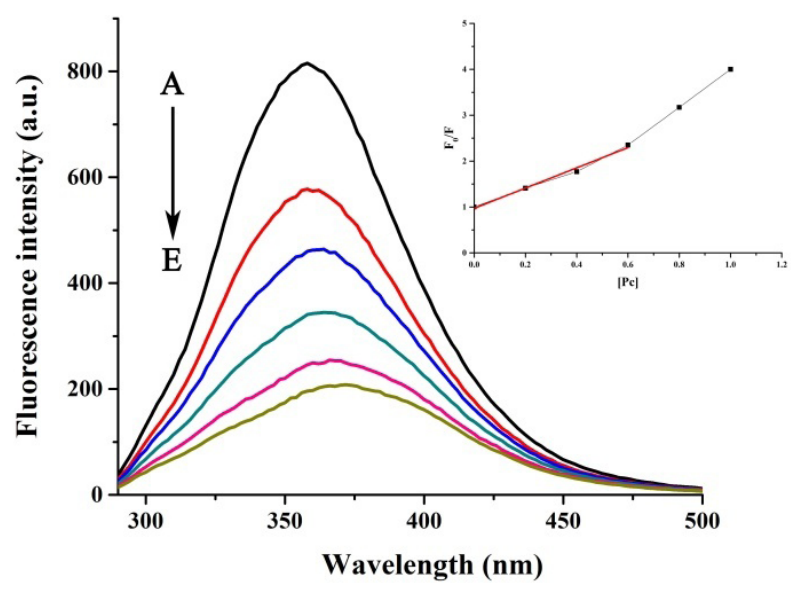

(b)

Fig. 3. Fluorescence spectra of BSA (a) and HSA (b) in PBS in the presence of different concentration of AlPc: A (black): 0; B (red): $0.2 \times 10^{-5}$; C (blue): $0.4 \times 10^{-5}$; D (dark cyan): $0.6 \times 10^{-5} ; \mathrm{E}$ (pink): $0.8 \times 10^{-5} ; \mathrm{F}$ (green): $1.0 \times 10^{-5} \mathrm{M}$. Insets: SternVolmer plots of fluorescence quenching of BSA and HSA versus AlPc complex concentration. 


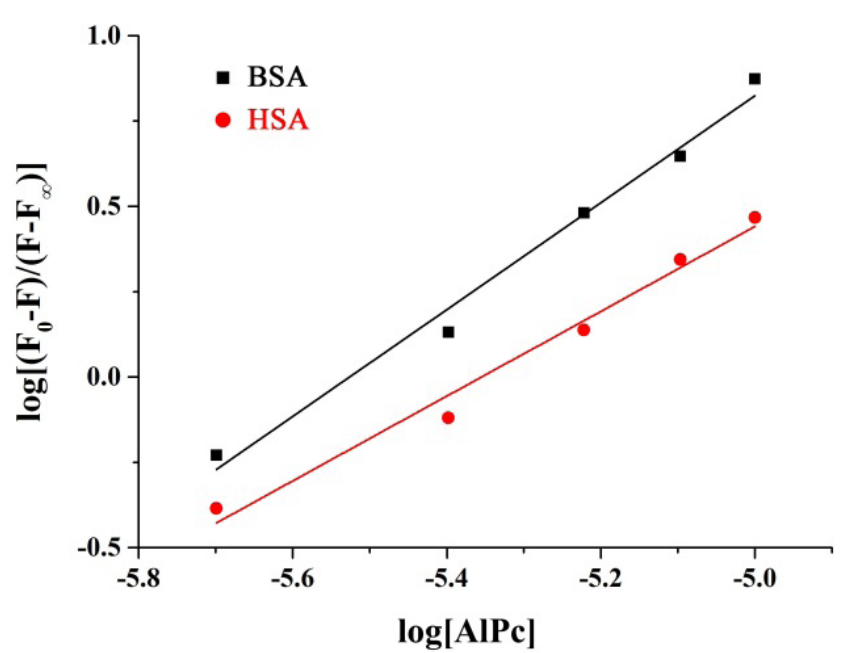

Fig. 4. Double logarithmic plots of fluorescence changes of serum albumins against different concentrations of AlPc complex. BSA: black filled square; HSA: red filled circle.

significantly after interacting with HSA than with BSA, and then led to the hydrophilia around the Trp residue of HSA becoming higher than that of BSA.

Fluorescence quenching, the decrease of the quantum yield of fluorescence from a fluorophore induced by a variety of molecular interactions with quencher molecule, ${ }^{26,27}$ is known as a useful method for measuring binding affinity. Therefore, the quenching of the intrinsic tryptophan fluorescence of BSA (Trp134 and Trp212) and HSA (Trp214) could be used to study the interactions of AlPc and serum albumins in order to characterize the nature of AlPc-protein complexation. ${ }^{12-15}$ There are two common fluorescence quenching mechanism namely static quenching and dynamic quenching. In the present study, the Stern-Volmer equation was used to elucidate the mechanism of fluorescence quenching of the BSA and HSA in the presence of different concentration of $\mathrm{AlPc}$ as previously reported. ${ }^{5}$

For BSA, as shown in the inset of Fig. 3(a), with the increase in $\mathrm{AlPc}$ concentration (from 0 to $\left.1.0 \times 10^{-5} \mathrm{~mol} / \mathrm{L}\right)$, the $K_{\mathrm{sv}}$ was determined to be
$3.38 \times 10^{5} \mathrm{M}^{-1}$, which was 1.53 times over that for HSA $\left(2.21 \times 10^{5} \mathrm{M}^{-1}\right.$, inset of Fig. 3(b)). The results indicated that the quenching rate of $\mathrm{BSA}$ was comparatively faster than that of HSA while interacting with AlPc. From the insets of Fig. 3, the Stern-Volmer plots curving upward at $0.4 \times 10^{-5} \mathrm{~mol} / \mathrm{L}$ and $0.6 \times 10^{-5} \mathrm{~mol} / \mathrm{L}$ for $\mathrm{BSA}$ and HSA respectively could also be found. The $K_{\mathrm{SV}}$ values of BSA and HSA are listed in Table 1, which are typical for Pc-BSA/HSA interactions. ${ }^{23,28,29}$ In certain concentrations, there is linear relationship between $\mathrm{F}_{0} / \mathrm{F}$ and $[\mathrm{Pc}]$ (Stern-Volmer curve) if the quenching type is single static or dynamic quenching. ${ }^{30}$ The proposed maximum value for dynamic quenching process at room temperature is $2.0 \times 10^{10} \mathrm{M}^{-1} \mathrm{~s}^{-1}, 31$ while $k_{q}$ in this study was found to be $10^{13} \mathrm{M}^{-1} \mathrm{~s}^{-1}$. The results indicated that the fluorescence quenching of BSA and HSA by AlPc was a static quenching process.

The binding sites $(n)$ and binding constants $\left(K_{b}\right)$ were further elucidated according to the previous reports. ${ }^{5,32}$ The results were shown in Fig. 4 and Table 1 . The significantly higher $K_{b}$ values for BSA indicated that AlPc bound to BSA much more strongly than that of HSA due to major hydrophilic and hydrophobic AlPc-BSA interactions. Moreover, the $n$ values were 1.57 and 1.24 in the AlPc-BSA and AlPc-HSA complexes, respectively, implying that there were two binding sites on BSA or only a single binding site on HSA for AlPc.

\subsection{Binding sites investigation}

In order to investigate the secondary binding sites of $\mathrm{AlPc}$ on serum proteins, a competitive binding reaction of $\mathrm{HE}$, IB and TRP with the AlPc/BSA complex were studied by UV/Vis spectra at both $\mathrm{AlPc}$ and BSA concentrations of $1 \times 10^{-5} \mathrm{~mol} / \mathrm{L}$. These conditions could provide detailed messages of the distribution of AlPc on different binding sites of BSA. According to the previous report, ${ }^{33}$ the molar ratios of $\mathrm{AlPc} / \mathrm{HE}, \mathrm{AlPc} / \mathrm{IB}$ and $\mathrm{AlPc} / \mathrm{TRP}$ were $1 / 20,1 / 20$ and $1 / 1000$, respectively, with the

Table 1. Binding and fluorescence quenching parameters for the interaction of AlPc with BSA and HSA.

\begin{tabular}{lcccc}
\hline Compounds & $K_{\mathrm{sv}} \times 10^{5}\left(M^{-1}\right)$ & $k_{q} \times 10^{13}\left(M^{-1} s^{-1}\right)$ & $K_{b}\left(M^{-1}\right)$ & $n$ \\
\hline BSA & $3.38\left(\mathrm{R}^{2}=0.9890\right)$ & 5.38 & $4.47 \times 10^{8}\left(\mathrm{R}^{2}=0.9831\right)$ & 1.57 \\
HSA & $2.21\left(\mathrm{R}^{2}=0.9834\right)$ & 2.21 & $4.52 \times 10^{6}\left(\mathrm{R}^{2}=0.9773\right)$ & 1.24 \\
\hline
\end{tabular}




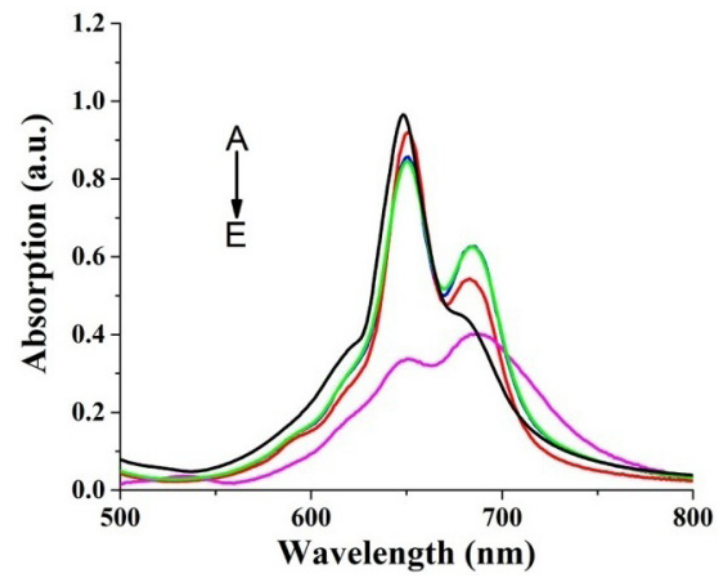

(a)

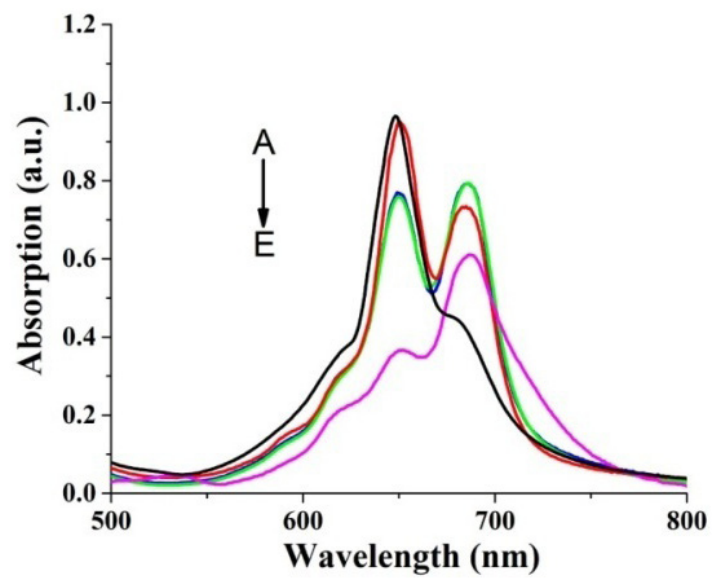

(b)

Fig. 5. Effects of HE, IB and TRP on absorption spectra of AlPc-BSA system. (a) The AlPc/BSA ratio is1/1. A-E represents AlPc (black, $1 \times 10^{-5} \mathrm{~mol} / \mathrm{L}$ ), AlPc+BSA+TRP (red, 1:1:1000), AlPc+BSA+IB (blue, 1:1:20), AlPc+BSA (green, 1:1) and AlPc+B$\mathrm{SA}+\mathrm{HE}$ (pink, 1:1:20). (b) The AlPc/BSA ratio is 1/10. A-E represents AlPc (black, $\left.1 \times 10^{-5} \mathrm{~mol} / \mathrm{L}\right), \mathrm{AlPc}+\mathrm{BSA}+\mathrm{TRP}(\mathrm{red}$, 1:10:1000), AlPc+BSA+IB (blue, 1:10:20), AlPc+BSA (green, 1:10) and AlPc+BSA+HE (pink, 1:10:20).

concentrations $2 \times 10^{-4} \mathrm{~mol} / \mathrm{L}, 2 \times 10^{-4} \mathrm{~mol} / \mathrm{L}$ and $1 \times 10^{-2} \mathrm{~mol} / \mathrm{L}$, respectively, were used in the experiment in order to provide competitive displacement of the bound AlPc. As shown in Fig. 5(a), the AlPc/BSA complex (Fig. 5(a), curve D) was not disturbed by the addition of IB (Fig. 5(a), curve C). On the contrary, titration of HE (Fig. 5(a), curve E) and TRP (Fig. 5(a), curve B) showed gradual changes in the absorption spectra comparing to the AlPc/BSA complex (Fig. 5(a), curve D). It might be deduced that AlPc could be replaced by the $\mathrm{HE}$

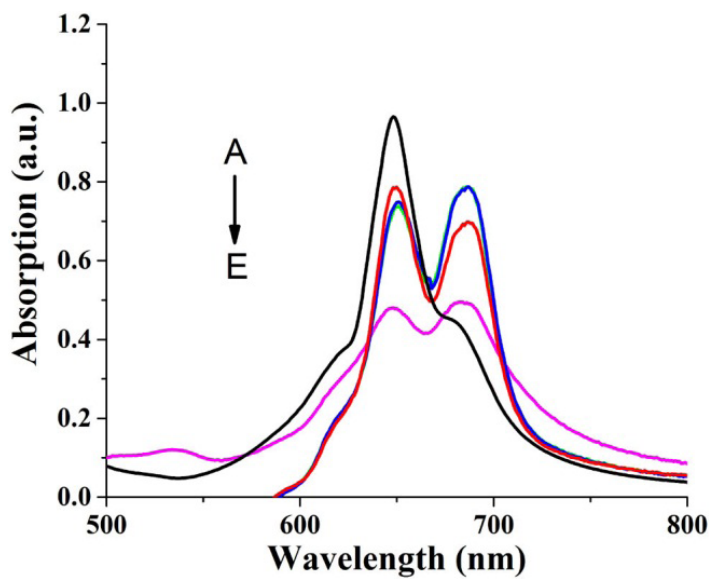

(a) and TRP from the AlPc/BSA complex. Therefore, the binding sites of AlPc overlapping that of $\mathrm{HE}$ and TRP were located on domains I and III of BSA. The competitive binding reaction to the AlPc/BSA complex was further performed at $\mathrm{AlPc}$ and BSA concentrations of $1 \times 10^{-5} \mathrm{~mol} / \mathrm{L}$ and $1 \times$ $10^{-4} \mathrm{~mol} / \mathrm{L}$, respectively, to identify the primary binding sites of AlPc. These conditions could make the special competitive ligands bind to the secondary site insignificantly. As shown in Fig. 5(b), similar changes in absorption spectra were found

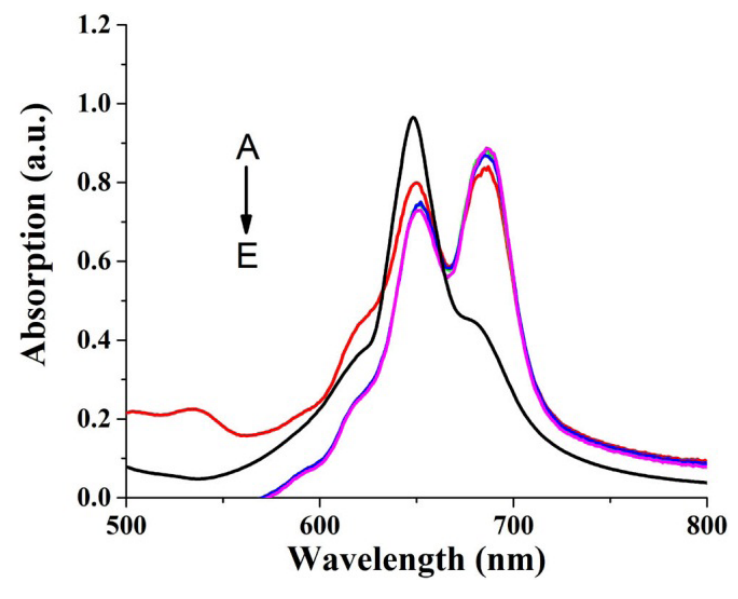

(b)

Fig. 6. Effects of HE, IB and TRP on absorption spectra of AlPc-HSA system. (a) The AlPc/HSA ratio is 1/1. A-E represents AlPc (black, $1 \times 10^{-5} \mathrm{~mol} / \mathrm{L}$ ), AlPc+HSA+IB (red, 1:1:20), AlPc+HSA+TRP (blue, 1:1:1000), AlPc+HSA (green, 1:1) and $\mathrm{AlPc}+\mathrm{HSA}+\mathrm{HE}$ (pink, 1:1:20). (b) The AlPc/HSA ratio is 1/10. A-E represents AlPc (black, $1 \times 10^{-5} \mathrm{~mol} / \mathrm{L}$ ), AlPc $+\mathrm{HSA}+\mathrm{HE}$ (red, 1:10:20), AlPc+HSA+IB (blue, 1:10:20), AlPc+HSA+TRP (green, 1:10:1000) and AlPc+HSA (pink, 1:10). 
comparing to the AlPc/BSA (1:1) system. So the primary binding sites of AlPc to BSA were located on domains I and III of BSA.

Similar experiments were performed to identify the secondary and primary binding sites of AlPc on the HSA. The concentrations of AlPc and HSA were both $1 \times 10^{-5} \mathrm{~mol} / \mathrm{L}$ in attempting to identify the secondary binding site of AlPc. The concentrations of binding ligands in the study were the same as that in the AlPc/BSA competive reaction. Representative absorption spectra of competitive reaction was shown in Fig. 6(a). No disturbance of AlPc binding to HSA was observed after adding TRP (Fig. 6(a), curve C). While titration of AlPc/HSA complex (Fig. 6(a), curve D) by HE (Fig. 6(a), curve E) and IB (Fig. 6(a), curve B) showed significant changes. Hence, the secondary binding sites of AlPc coincided with the main ligand binding regions of domains I and II. Further, in order to identify the primary binding sites of $\mathrm{AlPc}$, the concentrations of $1 \times 10^{-5} \mathrm{~mol} / \mathrm{L}$ and $1 \times 10^{-4} \mathrm{~mol} / \mathrm{L}$ corresponding to AlPc and BSA respectively, were chosed. No disturbance of AlPc binding to HSA was observed after adding IB (Fig. 6(b), curve C) and TRP (Fig. 6(b), curve D). While titration of AlPc/ HSA complex (Fig. 6(b), curve E) by HE (Fig. 6(b), curve B) showed significant changes. Thus, the primary binding site of AlPc to HSA was domain I of HSA.

\section{Conclusion}

AlPc was readily bound with BSA and HSA to form more stable conjugates. The primary and secondary binding sites of AlPc to BSA were on domains I and III of BSA. The primary binding site of AlPc on HSA was found to be domain I of HSA, and the secondary binding sites were on domains I and II of HSA. AlPc-BSA interaction and AlPc-HSA interaction may alter the secondary structure of BSA and HSA, because red shifts of maximum emission wavelength were observed. It is clearly shown that BSA and HSA can transport AlPc in vitro.

\section{Acknowledgments}

This work was supported in part by the National Key Basic Research Program of China under Grant No. 2015CB352006, the National Natural
Science Foundation of China under Grant Nos. 61335011 and 21274021, the Program for Changjiang Scholars and Innovative Research Team in University under Grant No. IRT15R10, the National High Technology Research and Development Program of China under Grant No. 2015AA020508 and Natural Science Foundation of Fujian Province under Grant Nos. 2015J01040 and 2014J01225.

\section{References}

1. R. Weijer, M. Broekgaarden, R. F. van Golen et al., "Low-power photodynamic therapy induces survival signaling in perihilar cholangiocarcinoma cells," BMC Cancer 15, 1014 (2015).

2. Y. C. Bae, E. Ng, R. G. Geronemus, "Successful treatment of two pediatric port wine stains in darker skin types using $595 \mathrm{~nm}$ laser," Lasers Surg. Med. 48(4), 339-342 (2016).

3. A. Kawczyk-Krupka, A. M. Bugaj, M. Potempa, K. Wasilewska, W. Latos, A. Sieroń, "Vascular-targeted photodynamic therapy in the treatment of neovascular age-related macular degeneration: clinical perspectives," Photodiagn. Photodyn. Ther. 12(2), 161-175 (2015).

4. D. E. Dolmans, D. Fukumura, R. K. Jain, "Photodynamic therapy for cancer," Nat. Rev. Cancer 3(5), 380-387 (2003).

5. Y. P. He, L. Q. Zheng, Y. D. Huang et al., Spectroscopic studies of the interaction between tetrasubstituted aluminum phthalocyanines and bovine serum albumin, Proc. SPIE, Vol. 92682 A Photonics Asia, Beijing (2014).

6. Y. Sadzuka, K. Tokutomi, F. Iwasaki et al., "The phototoxicity of photofrin liposome was enhanced by PEGy lated in vitro," Cancer Lett. 241(1), 42-48 (2006).

7. R. F. V. Lopez, N. Lange, R. Guy et al., "Photodynamic therapy of skin cancer: Controlled drug delivery of 5-ALA and its esters," Adv. Drug. Deliv. Rev. 56(1), 77-94 (2004).

8. P. Agostinis, K. Berg, K. A. Cengel et al., "Photodynamic therapy of cancer: An update," $C A$ Cancer J. Clin. 61(4), 250-281 (2011).

9. Z. Chen, Y. X. Zhang, D. Wang et al., "Photodynamic antimicrobial chemotherapy using zinc phthalocyanine derivatives in treatment of bacterial skin infection," J. Biomed. Opt. 21(1), 018001 (2015).

10. D. Çakir, V. Çakir, Z. Biyiklioğlu, M. Durmuş, H. Kantekin, "New water soluble cationic zinc phthalocyanines as potential for photodynamic therapy of cancer," J. Orgnomet. Chem. 745-746, 423-431 (2013). 
11. M. Voicescu, D. G. Angelescu, S. Ionescu, V. S. Teodorescu, "Spectroscopic analysis of the riboflavinserum albumins interaction on silver nanoparticles," J. Nanopart. Res. 15(4), 1555 (2013).

12. D. Agudelo, P. Bourassa, J. Bruneau et al., "Probing the binding sites of antibiotic drugs doxorubicin and $\mathrm{N}$-(trifluoroacetyl) doxorubicin with human and bovine serum albumins," PloS One 7(8), e43814 (2012).

13. T. Peters Jr., All about albumin: Biochemistry, Genetics \& Medical Applications, San Diego, CA, Academic Press, California (1995).

14. D. Pangeni, C. Kapil, M. A. Jairajpuri, P. Sen, "Inter-domain helix h10DOMI-h1DOMII is important in the molecular interaction of bovine serum albumin with curcumin: Spectroscopic and computational analysis," Eur. Biophys. J. 44(3), 139-148 (2015).

15. A. Varshney, P. Sen, E. Rehan, N. Subbarao, R. H. Khan, "Ligand binding strategies of human serum albumin: How can the cargo be utilized?" Chirality 22(1), 77-87 (2010).

16. H. Ali, R. Langlois, J. R. Wagner, N. Brasseur, B. Paquette, J. E. van Lier, "Biological activities of phthalocyanines - X. Syntheses and analyses of sulfonated phthalocyanines," Photochem. Photobiol. 47(5), 713-717 (1988).

17. J. Y. Liu, X. J. Jiang, W. P. Fong, D. K. Ng, "Highly photocytotoxic 1, 4-dipegylated zinc (II) phthalocyanines. Effects of the chain length on the in vitro photodynamic activities," Org. Biomol. Chem. 6(24), 4560-4566 (2008).

18. R. Bayrak, F. Dumludağ, H. T. Akçay, I. Değirmencioğlu, "Synthesis, characterization and electrical properties of peripherally tetra-aldazine substituted novel metal free phthalocyanine and its zinc (II) and nickel (II) complexes," Spectrochim. Acta Mol. Bilmol. Spectrosc. 105, 550-556 (2013).

19. R. Bayrak, H. T. Akçay, F. Ş. Beriş, E. Sahin, H. Bayrak, Ü. Demirbaş, "Synthesis, aggregation and spectroscopic studies of novel water soluble metal free, zinc, copper and magnesium phthalocyanines and investigation of their anti-bacterial properties," Spectrochim. Acta A Mol. Biomol. Specrosc. 133, 272-280 (2014).

20. D. Ma, P. Lin, L. Chen et al., "Synthesis of poly (ethyleneglycol) -poly(L-lysine) diblock copolymer incorporating tetra- $(p$-sulfoazophenyl-4-aminosulfonyl) phthalocyanine chloride aluminum (III) polyion nanoparticles and its in vitro photodynamic therapy efficacy," Chem. J. Chinese U 33(7), 1456-1461 (2012).

21. X. Y. Li, X. He, A. C. H. Ng et al., "Influence of surfactants on the aggregation behavior of water-soluble dentritic phthalocyanines," Macromolecules 33, 2119-2123 (2000).

22. Y. J. Hu, Y. Liu, Z. B. Pi, S. S. Qu, "Interaction of cromolyn sodium with human serum albumin: A fluorescence quenching study," Bioorg. Med. Chem. 13, 6609-6614 (2005).

23. M. Durmuş, H. Yaman, C. Göl, V. Ahsen, T. Nyokong, "Water-soluble quaternized mercaptopyridine-substituted zinc-phthalocyanines: synthesis, photophysical, photochemical and bovine serum albumin binding properties," Dyes Pigment. 91(2), 153-163 (2011).

24. X. Jia, F. F. Yang, J. Li et al., "Synthesis and in vitro photodynamic activity of oligomeric ethylene glycol-quinoline substituted zinc (II) phthalocyanine derivatives," J. Med. Chem. 56(14), 5797-5805 (2013).

25. SeHyun Jung, S. J. Choi, H. J. Kim et al., "Molecular characteristics of bovine serum albumindextran conjugates," Biosci. Biotechnol. Biochem. 70, 2064-2070 (2006).

26. N. Tayeh, T. Rungassamy, J. R. Albani, "Fluerescence spectral resolution of tryptophan residues in bovine and human serum albumins," $J$. Pharm. Biomed. Anal. 50, 107-116 (2009).

27. J. R. Lakowicz, in Principles of Fluorescence Spectroscopy, 3rd edition, Spring, New York (2006).

28. S. Tuncel, F. Dumoulin, J. Gailer et al., "A set of highly water-soluble tetraethyleneglycol-substituted Zn (II) phthalocyanines: Synthesis, photochemical and photophysical properties, interaction with plasma proteins and in vitro phototoxicity," Dalton Trans. 40(16), 4067-4079 (2011).

29. C. Uslan, B. Ş. Sesalan, M. Durmu, "Synthesis of new water soluble phthalocyanines and investigation of their photochemical, photophysical and biological properties," J. Photochem. Photobiol. A Chem. 235, 56-64 (2012).

30. M. Ranjian, P. Diffley, G. Stenphen, D. Proce, "Comparative study of human steroid $5 \alpha$-reductase isoforms in prostate and female breast skin tissues: Sensitivity to inhibition by finasteride and epristeride," Life Sci. 71, 115-126 (2002).

31. S. L. Murov, I. Carmichael, G. L. Hug, Handbook of Photochemistry, CRC Press, New York (1993).

32. A. Ogunsipe, T. Nyokong, "Photophysicochemical consequences of bovine serum albumin binding to non-transition metal phthalocyanine sulfonates," Photochem. Photobiol. Sci. 4(7), 510-516 (2005).

33. A. I. Filyasova, I. A. Kudelina, A. V. Feofanov, "A spectroscopic study of the interaction of tetrasulfonated aluminum phthalocyanine with human serum albumin," J. Mol. Struct. 565-566, 173-176 (2001). 